\title{
THE ROLE OF PRINCIPAL IN CURRICULUM AND LEARNING MANAGEMENT
}

\section{Bening Sri Palupi, Ervina Esti}

Universitas Sebelas Maret

beninglupi@gmail.com

\section{Article History}

accepted 09/07/2018

approved 01/08/2018

published 17/09/2018

\section{Keywords}

role of principal, curriculum management, learning

management

\begin{abstract}
This study aims to describe the role of school principals in curriculum and learning management at SDN Manahan Banjasarsari District Surakarta City. The formulation of this research is how the role of school principals in curriculum and learning management, to obtain the data used interview techniques and filling questionnaires. The validity of the data is done by means of source triangulation, ie analyzing the results of interviews and questionnaires based on the theory used and relevant research studies as a comparison material. Data analysis technique used is interactive analysis. The results can be concluded that the role of school principals in curriculum management and learning in SDN Manahan is more likely to play a role as a curriculum tool maker. This can be seen from the headmaster not only providing socialization of the 2013 curriculum to teachers and school committees, but also providing socialization to parents.
\end{abstract}

Social, Humanities, and Education Studies (SHEs): Conference Series https://jurnal.uns.ac.id/shes

p-ISSN 2620-9284 e-ISSN 2620-9292 


\section{PENDAHULUAN}

Tugas kepala sekolah yang berkenaan dengan manajemen kurikulum dan pembelajaran berhubungan dengan kompetensi kepala sekolah dalam memahami sekolah sebagai sistem yang harus dipimpin dan dikelola dengan baik, diantaranya pengetahuan tentang manajemen itu sendiri. Rusman (2011:10) mengemukakan kemampuan dalam mengelola akan dijadikan sebagai pegangan, cara berpikir, cara mengelola, dan cara menganalisis sekolah dengan cara berpikir seorang manajer. Kepala sekolah harus mampu memahami kinerja dalam hal mengidentifikasi dan mengembangkan jenis-jenis input sekolah; mengembangkan proses sekolah (proses pembelajaran, koordinasi, motivasi, pemantauan, supervise, evaluasi, akreditasi, pengambilan keputusan, dan pemberdayaan).

Lebih lanjut, Rusman mengungkapkan bahwa kepala sekolah harus memahami bahwa dirinya harus mampu menunjukkan upaya dalam meningkatkan output sekolah, yaitu kualitas, produktivitas, efisiensi, dan inovasi. Lain halnya dengan Rusman, Triwiyanto (2015:70-71) mengemukakan tugas kepala sekolah yang berkenaan dengan manajemen kurikulum dan pembelajaran pada kompetensi manajerial diantaranya sebagai berikut: (a) mengadakan rapat pendidik dan tenaga kependidikan; (b) mengadakan evaluasi terhadap semua kegiatan sekolah; (c) menyelenggarakan evaluasi bagi siswa dan ujian sekolah; (d) menyusun penjabaran kalender pendidikan; (e) menyusun dan mengelola evaluasi pembelajaran; dan (f) menyusun kriteria dan persyaratan naik/tidak naik kelas dan lulus/tidak lulus.

Berdasarkan uraian di atas, maka peneliti termotivasi untuk mengkaji peran kepala sekolah dalam manajemen kurikulum dan pembelajaran karena menyangkut kompetensi yang dimiliki kepala sekolah untuk memahami bahwa sekolah adalah sebagai suatu sistem yang harus dipimpin, karena kepemimpinan merupakan kemampuan untuk mempengaruhi orang lain agar bekerja mencapai tujuan dan sasaran yang diharapkan. Sehubungan dengan hal itu, Triwiyanto (2015:64) menggambarkan sistem kerja kepala sekolah sebagai berikut:

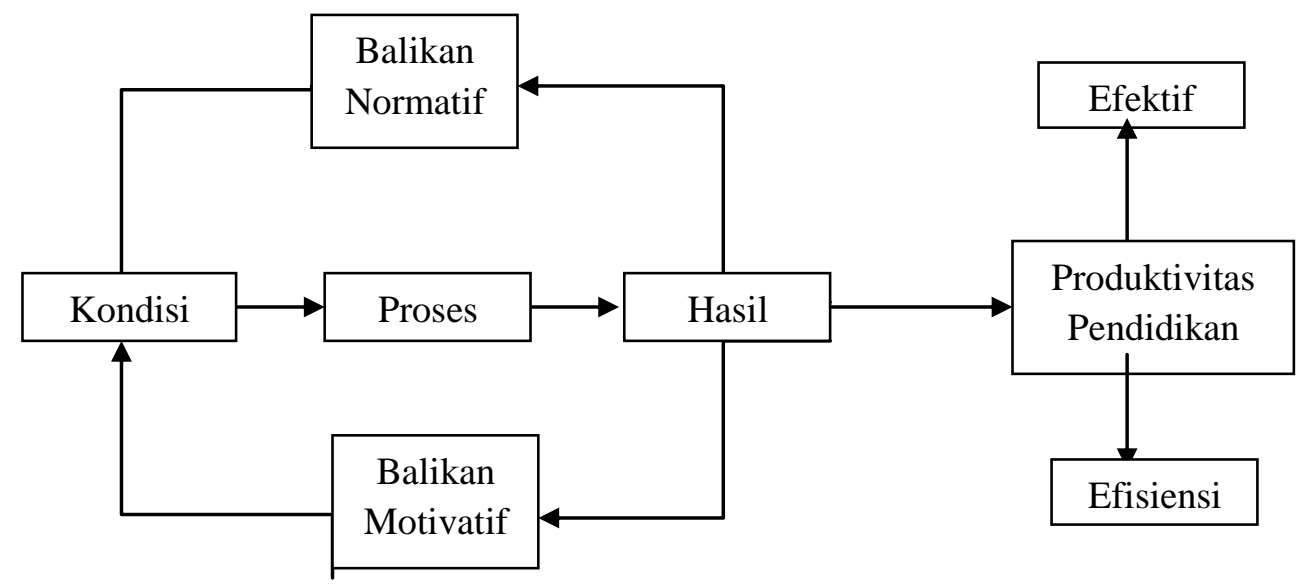

Gambar tersebut menunjukkan tanggung jawab kepala sekolah adalah menjamin tercapainya hasil pendidikan sebaik mungkin dengan mengordinasikan sistem kerja sekolah secara produktif. Semua masukan diperlukan sebagai kondisi awal yang akan diproses untuk mencapai hasil yang diinginkan. Hasil sistem menjadi balikan normatif untuk memperbaiki kuantitas hasil, sementara balikan motivasi digunakan sebagai perbaikan kualitas. Hasil dapat diukur melalui produktivitas pendidikan berupa efektivitas dan efisiensinya.

Berdasar pada pendapat Triwiyanto di atas, maka untuk mendeskripsikan peran kepala sekolah dalam manajemen kurikulum dan pembelajaran di SDN Manahan dapat digambarkan sebagai berikut: 


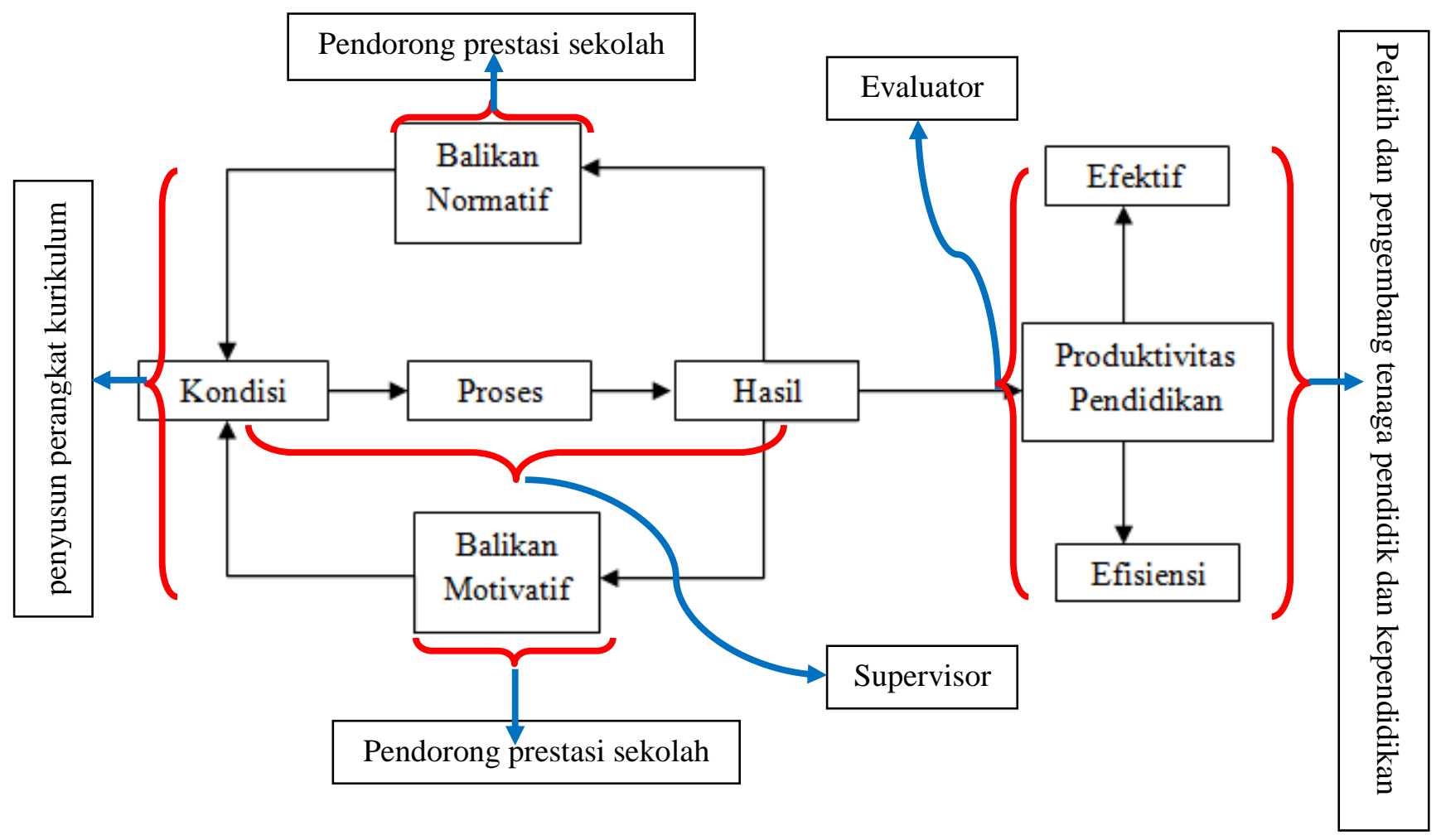

Manajemen kurikulum dan pembelajaran tidak hanya melibatkan kompetensi sekolah dalam hal manajerial saja. Dean (2002:12) berpendapat bahwa "The personality of a headteacher is crucial to his or her success but it should not be the only criterion. Appointing committees need to remember that any managerial post involves the ability to undertake specific tasks and the appointing committee needs to ensure that the successful candidate has experience of a number of these tasks and has the kind of approach and skill which will enable him or her to learn how to cope with new ones". Pendapat tersebut dapat diartikan bahwa kepribadian kepala sekolah sangat penting untuk kesuksesannya, tetapi bukan satu-satunya kriteria. Menujuk komite/penugasan, perlu diingat bahwa setiap jabatan manajerial melibatkan kemampuan untuk melakukan tugas-tugas tertentu dan komite menunjuk pada kebutuhan untuk memastikan bahwa keberhasilan kandidat yang berpengalaman pada sejumlah tugas ini memiliki jenis pendekatan serta keterampilan yang akan memungkinkan dia untuk belajar bagaimana untuk mengatasi dengan cara yang baru.

Berkaitan dengan manajemen pembelajaran, Zaitseva, Bule and Makarov (2013:412) berpendapat bahwa "The component-based approach to develop learning management system allows reducing time and other resources consumption. Since this approach is based on the reusable components using to create a new product it also facilitates the whole process". Itu artinya pendekatan berbasis komponen untuk mengembangkan sistem manajemen pembelajaran memungkinkan mengurangi waktu dan sumber daya lainnya. Oleh karena itu, pendekatan berbasis komponen dapat digunakan lagi untuk menciptakan produk baru yang juga memfasilitasi keseluruhan proses. Berdasarkan pendapat ini, dapat diketahui bahwa manajemen pembelajaran yang baik yaitu mampu mencapai efektivitas dan efisiensi dari segi waktu dan biaya sehingga dapat memberikan hasil akhir yang sesuai dengan perencanaan.

Berangkat dari paparan di atas, untuk mendapatkan data terkait peran kepala sekolah dalam manajemen kurikulum dan pembelajaran di SDN Manahan, peneliti hanya berfokus pada lima peran yang dikembangkan dari teori sistem kerja kepala sekolah dari Triwiyanto yang telah diuraikan sebelumnya. Adapun peran-peran 
tersebut yaitu (1) pendorong prestasi sekolah; (2) penyusun perangkat kurikulum, (3) Pelatih dan pengembang tenaga pendidik dan kependidikan, (4) supervisor, dan (5) evaluator.

\section{METODE PENELITIAN}

Penelitian ini dilakukan di SDN Manahan, Kota Surakarta. Penelitian ini merupakan penelitian deskriptif kualitatif. Teknik pengumpulan data menggunakan wawancara dan pengisian kuisioner. Validitas data dilakukan dengan cara triangulasi sumber, yaitu menganalisis hasil wawancara dan kuisioner berdasarkan teori yang digunakan dan kajian penelitian yang relevan sebagai bahan pembanding. Teknik analisis data yang digunakan adalah analisis interaktif yang terdiri dari empat tahap yaitu pengumpulan data, reduksi data, penyajian data, dan penarikan kesimpulan atau verifikasi.

\section{HASIL PENELITIAN DAN PEMBAHASAN \\ A. Peran Kepala Sekolah sebagai Pendorong Prestasi Sekolah}

Triwiyanto (2015:64) mengemukakan sistem kerja kepala sekolah dalam menjamin tercapainya hasil pendidikan bergantung pada bagaimana dia mengoordinasikan sistem kerja sekolah secara produktif. Salah satu bentuk keberhasilan sistem tersebut dapat ditunjukkan dari segi kuantitas. Berdasar dari pendapat tersebut, maka untuk mengetahui peran kepala sekolah sebagai pendorong prestasi dapat dilihat dari banyaknya penghargaan atau prestasi siswa dalam bentuk karya dan keterampilan. SDN Manahan selalu mendapatkan juara dalam berbagai lomba, baik dalam bentuk karya maupun keterampilan. Sekolah tersebut mendapatkan antara 1-2 penghargaan per tahun baik dari tingkat kecamatan sampai tingkat nasional. Jika dijumlahkan seluruh penghargaan/piala dalam satu tahun ada delapan, sehingga kinerja kepsek dalam hal ini berada pada tingkat baik.

Hal di atas diperjelas dalam wawancara bahwa kepala sekolah selalu memberikan balikan yang berupa normatif maupun motivatif untuk meningkatkan kuantitas penghargaan yang diperoleh dan kualitasnya itu sendiri. Balikan normatif berupa kepala sekolah yang selalu memberikan arahan kepada guru agar targettarget akademik dan non akademik siswa yang telah direncanakan dapat tercapai dan mampu meningkatkan kinerjanya. Dalam hal ini mampu mengantarkan siswa meraih juara berbagai lomba. Balikan motivatif juga dilakukan dengan memberikan penghargaan kepada siswa, misalnya siswa yang mendapatkan kejuaraan diberikan hadiah tambahan dari sekolah. Hadiah tersebut berupa barang-barang yang terkait dengan kebutuhan sekolah.

Serupa dengan hasil penelitian ini, Salmiati dan Afridzal (2018:33) menemukan bahwa kepala sekolah di SD Negeri 19 Banda Aceh melakukan pendekatan secara pribadi untuk memotivasi siswa dalam meningkatkan prestasinya. Dengan pendekatan individu, permasalahan yang dihadapi seorang siswa dapat ditangani dengan tepat. Pendekatan secara individu juga dapat memberikan rasa nyaman kepada siswa, sehingga terjalin hubungan yang baik antara guru dan siswa. Sedangkan peran kepala sekolah SDN Manahan sebagai pendorong prestasi memang cukup baik, tetapi kepala sekolah lebih berfokus pada pemberian penghargaan kepada siswa dan guru yang telah berhasil mendapatkan kejuaraan. 


\section{B. Peran Kepala Sekolah sebagai Penyusun Perangkat Kurikulum}

Triwiyanto menunjukkan tanggung jawab kepala sekolah adalah menjamin tercapainya hasil pendidikan sebaik mungkin dengan mengordinasikan sistem kerja sekolah secara produktif. Semua masukan diperlukan sebagai kondisi awal yang akan diproses untuk mencapai hasil yang akan diproses untuk mencapai hasil yang diinginkan. Kondisi awal ditentukan oleh kepala sekolah dalam menyusun perangkat kurikulum.

Berdasarkan jawaban kuisioner, perangkat kurikulum yang dimiliki dan/atau dibuat oleh kepala sekolah SDN Manahan yaitu kurikulum 2013, pedoman kurikulum tingkat satuan pendidikan pada pendidikan dasar, pedoman muatan lokal kurikulum 2013, pedoman kegiatan ektrakurikuler pada pendidikan dasar, pedoman pembelajaran pada pendidikan dasar, pedoman penilaian hasil belajar oleh pendidik pada pendidikan dasar, pedoman bimbingan dan konseling pada pendidikan dasar, pedoman evaluasi kurikulum 2013, pedoman pendampingan pelaksanaan kurikulum 2013 pada pendidikan dasar, dan pedoman pendidikan kepramukaan sebagai kegiatan ekstrakurikuler wajib pada pendidikan dasar.

Selain membuat perangkat kurikulum, kepala sekolah juga memberikan sosialisasi tentang kurikulum baru yaitu kurikulum 2013. Sosialisasi yang hanya dilakukan kepada guru yaitu pedoman pembelajaran pada pendidikan dasar, pedoman penilaian hasil belajar oleh pendidik pada pendidikan dasar, pedoman bimbingan dan konseling pada pendidikan dasar, pedoman evaluasi kurikulum 2013, pedoman pendampingan pelaksanaan kurikulum 2013 pada pendidikan dasar, dan pedoman pendidikan kepramukaan sebagai kegiatan ekstrakurikuler wajib pada pendidikan dasar. Sosialisasi yang dilakukan kepada guru dan komite sekolah yaitu pedoman kurikulum tingkat satuan pendidikan pada pendidikan dasar, pedoman muatan lokal kurikulum 2013, pedoman kegiatan ektrakurikuler pada pendidikan dasar. Mengenai kurikulum baru yaitu kurikulum 2013, kepala sekolah juga tidak hanya memberikan sosialisai kepada guru dan komite, melainkan juga memberikan sosialisasi kepada orang tua. Hal ini sejalan dengan penelitian Alkahtani (2017:1) yang menemukan bahwa "The importance of open communication, and a bottom-up as well as a top-down flow of decision-making. Communication and decisions flow down to the middle managers, and the reactions and opinions of those at the bottom may or may not flow back up to the decisionmakers at the top". Itu artinya pentingnya komunikasi terbuka baik komuniskasi dari bawah atas ataupun atas bawah dalam mengambil keputusan. Komunikasi dan keputusan mengalir kepada penengah dan reaksi serta pendapat tersebut yang berada di bawah mungkin atau tidak mungkin mengalir kembali ke pembuat keputusan di atas. Kepala SDN Manahan berkomunikasi secara terbuka kepada semua pihak yang terlibat untuk menyusun kurikulum.

Kurikulum yang digunakan di SDN Manahan yaitu kurikulum 2013 untuk kelas 1, 2, 4, dan 5. Kurikulum KTSP untuk kelas 3 dan 6. Kepala sekolah tetap menggunakan landasan yuridis dari pemerintah pusat dalam menyusun kurikulum yaitu UU Nomor 20 tahun 2003, permendikbud nomor 67 tahun 2013, permendikbud nomor $81 \mathrm{~A}$ tentang implementasi kurikulum. Penyusunan kurikulum melibatkan guru, komite, pengawas, dinas, dan tokoh masyarakat. Kemudian untuk penyempurnaan silabus sekolah, kepala sekolah hanya menyempurnakan sumber belajarnya saja. Hal ini sejalan dengan Pata, dkk (2016:297-298) yang mengemukakan bahwa "Curriculum maturing is an annual cycle that starts from accessing the normalized set of National Standards (such as professional qualifications, nationally expected outcomes etc.) which prescribe for curricula certain norms". Itu artinya, penyempurnaan kurikulum merupakan sebuah siklus tahunan yang dimulai dari mengakses standar nasional yang ditetapkan (seperti 
kualifikasi profesional, hasil yang diharapkan secara nasional, dll.) yang menentukan norma-norma kurikulum tertentu.

Penyusunan kurikulum dilakukan sesuai rencana progam sekolah. Rencana program sekolah di SDN Manahan disusun bersama-sama waka sekolah, guru, komite, pengawas dan stakeholder. Langkah pertama adalah menyusun visi sekolah. Dari visi kemudian dijabarkan ke dalam misi. Dan untuk mencapai misi tersebut, dibuat tujuan-tujuan sekolah yang kemudian dijabarkan dalam berbagai program-program kerja. Baik rencana program kerja dalam jangka pendek, menengah maupun panjang. Pelaksanaannya menyesuaikan progam-progam yang telah direncanakan. Selanjutnya, muatan lokal kurikulum yang dikembangkan di SDN Manahan yaitu mengembangkan seni daerah jawa yaitu seni suara daerah dan tari. Seperti yang diungkapkan Chitrangsan, Sawekngam, dan Thongthew (2015:164) bahwa "Curriculum management process based on Lean waste elimination concepts to enhance efficiency of curriculum application consists of the following principles. These are: (1) determination of concrete and clear target must be simple, measurable, achievable, reasonable, and trackable; and (2) development of value chain is a concrete process allowing relevant parties to see clear picture overall in order to share common understanding on targets. Itu artinya, proses manajemen kurikulum berdasarkan konsep penghapusan kerugian yang buruk untuk meningkatkan efisiensi penerapan kurikulum terdiri dari prinsip-prinsip berikut: (1) penentuan target yang jelas dan jelas harus sederhana, dapat diukur, dapat dicapai, masuk akal, dan dapat dilacak; dan (2) pengembangan rantai nilai adalah proses konkret yang memungkinkan pihak terkait untuk melihat gambaran yang jelas secara keseluruhan untuk berbagi pemahaman umum tentang target.

Berdasarkan uraian di atas, peran kepala sekolah SDN Manahan sebagai penyusun perangkat kurikulum sangat menonjol. Hal ini dapat dilihat dari banyaknya serangkain aktivitas penyusunan kurikulum yaitu perangkat kurikulum KTSP, 2013, sampai pedoman kegiatan ekstrakurikuler disusun bersama-sama dengan melibatkan semua pihak yaitu guru, komite, tokoh masyarakat. Setelah menyusunnya, kepala sekolah juga memberikan sosialisasi kepada pihak-pihak tersebut ditambah sosialisasi kepada orang tua/wali siswa. Kepala sekolah juga melakukan rencana kerja dengan melibatkan semua pihak terkait rencana jangka pendek hingga panjang.

\section{Peran Kepala Sekolah sebagai Pelatih dan Pengembang Tenaga Pendidik dan Kependidikan}

Berdasarkan sistem kerangka kerja kepala sekolah, tanggung jawab kepala sekolah adalah menjamin tercapainya hasil pendidikan sebaik mungkin dengan mengordinasikan sistem kerja sekolah secara produktif. Maka dari itu, kepala sekolah harus mampu melatih sekaligus mengembangkan tenaga pendidik dan kependidikan. Aktivitas pelatihan dan pengembangan yang sering dilakukan yaitu penyusunan kurikulum, penyusunan rencana program pembelajaran, pengelolaan kelas, penilaian pendidikan, dan kewirausahaan. Kemudian, aktivitas pelatihan dan pengembangan yang jarang dilakukan yaitu keteladanan sebagai pendidik dan tenaga kependidikan, kepemimpinan di kelas, membangun sekolah aman, dan pengelolaan sarana dan prasarana pendidikan.

Kepala SDN Manahan tidak ada strategi khusus dalam melatih dan mengembangkan tenaga pendidik dan kependidikan, kepala sekolah hanya melibatkan semua pihak dalam mengembangkannya diantaranya guru, siswa, dan komite. Kemudian untuk mengembangkan muatan lifeskill agar pembelajaran yang dilakukan guru kelas dapat membentuk karakter siswa, kepala sekolah hanya mengadakan tutor sesame guru. Pengembangan guru dan staf dilakukan oleh dinas 
pendidikan maupun mengadakan sendiri dengan mendatangkan narasumber. Pengembangan guru dan staf melalui pengembangan karir dilakukan dengan mengajukan guru yang berprestasi sebagai kepala sekolah, namun tidak ada perlakuan khusus bagi staf lain dalam pengembangan karir. Dalam meningkatkan pembelajaran, kepala sekolah memberi motivasi kepada guru dan memberikan penghargaan kepada guru yang berprestasi misalnya berupa diajukan menjadi kepala sekolah. Hal ini sejalan dengan Pata, dkk (2016:297-298) bahwa "The Personal competence maturing cycle enables students to plan learning in a selfregulated way - using the personal portfolio they can propose their personal learning outcomes, map their knowledge gap, identify the courses that they plan to attend, model the personal curriculum, collect evidences of their learning while following the curriculum, and be evaluated based on these evidences". Itu artinya, penyempurnaan kompetensi kepribadian, siklus penyempurnaan kompetensi pribadi memungkinkan siswa untuk merencanakan pembelajaran dengan cara yang diatur sendiri menggunakan portofolio pribadi mereka sehingga dapat mengusulkan hasil pembelajaran pribadi mereka, memetakan kesenjangan pengetahuan mereka, mengidentifikasi kursus yang akan mereka hadiri, membuat model kurikulum pribadi, mengumpulkan bukti-bukti dari pembelajaran mereka saat mengikuti pelaksanaan kurikulum, dan dievaluasi berdasarkan bukti-bukti ini.

Berbeda dengan hasil penelitian ini, penelitian Syafrizal (2016:74) menemukan bahwa salah satu bentuk pengembangan dan peningkatan kompetensi guru yang dilakukan di SD Islam Plus Excellent Bukittinggi yaitu guru-guru juga mendapat pelatihan dari kepala sekoah yang mengundang tenaga ahli dari luar daerah seperti Jakarta dan Solo tentang pembuatan bahan ajar menggunakan ICT (Information Communication Technologies). Semua kegiatan-kegiatan pengembangan diri dilakukan dalam upaya peningkatan mutu dan kualitas pendidikan. Hal ini diperkuat oleh Dean (2002:12) yang mengungkapkan bahwa "Appointing committees need to remember that any managerial post involves the ability to undertake specific tasks and the appointing committee needs to ensure that the successful candidate has experience of a number of these tasks and has the kind of approach and skill which will enable him or her to learn how to cope with new ones". Itu artinya menujuk komite, perlu diingat bahwa setiap jabatan manajerial melibatkan kemampuan untuk melakukan tugas-tugas tertentu dan komite menunjuk pada kebutuhan untuk memastikan bahwa keberhasilan kandidat yang berpengalaman pada sejumlah tugas ini memiliki jenis pendekatan serta keterampilan yang akan memungkinkan dia untuk belajar bagaimana untuk mengatasi dengan cara yang baru.

Jadi, peran kepala sekolah SDN Manahan sebagai pelatih dan pengembang tenaga pendidik dan kependidikan tidak menonjol karena kepala sekolah tidak memiliki strategi khusus dalam melatih dan mengembangkannya. Padahal jika seorang kepala sekolah memiliki strategi khusus maka tenaga pendidik dan kependidikan lebih mudah terarah dalam melakukan rencana kerja sesuai harapan.

\section{Peran Kepala Sekolah sebagai Supervisor}

Beradasarkan bagan sistem kerja kepala sekolah dari Triwiyanto, menunjukkan bahwa semua masukan diperlukan sebagai kondisi awal yang akan diproses untuk mencapai hasil mencapai hasil yang diinginkan. Oleh karenanya, kepala sekolah bertindak sebagai supervisor yang harus mampu memberikan penilaian performasi guru dalam mengelola proses belajar mengajar sebagai suatu proses dalam mengelola penampilan guru dalam proses belajar mengajar. Kepala SDN Manahan menghendaki para guru untuk membuat RPP dalam jangka waktu per pertemuan yang diperiksa tiap hari efektif sekolah dan diperiksa tiap bulan oleh 
pengawas sekolah. Kepala SDN Manahan mengatakan bahwa sebagian besar kesulitan guru dalam menerapkan pembelajaran siswa aktif dan kreatif yaitu sarana dan prasarana yang terkadang tidak mendukung.

Berdasarkan data yang diambil dari kepala sekolah, RPP yang dibuat para guru SDN Manahan, indikatornya meliputi indikator sikap, pengetahuan, dan ketrampilan. Materi pembelajaran sudah kontekstual sesuai karakteristik lokal dan global. Materi pembelajaran terintegrasi dengan isu sosial, lingkungan, kesehatan baik di tingkat lokal, nasional, global. Namun, RPP belum berisi kegiatan pembelajaran yang menerapkan berbagai metodologi dan pendekatan, belum melibatkan masyarakat (orang tua, petani, aparat pemerintah, dll), belum menggunakan berbagai sumber belajar yang berupa alam, museum, pabrik, pasar, dll. Kemudian media belajar yang berupa internet dan buku bacaan juga belum dioptimalkan. Hal ini diperkuat oleh Sobri (2013:9) yang menemukan bahwa peran kepala sekolah sebagai supervisor adalah meningkatkan keberhasilan keseluruhan progam pembelajaran sekolah dengan membantu guru memecahkan masalah pembelajaran di kelas. Teknik supervisi yang dilakukan oleh kepala sekolah antara lain kunjungan kelas, pertemuan pribadi, rapat rutin, kunjungan antarsekolah, pertemuan dalam kelompok kerja, pelatihan, dan penataran.

Pembuatan RPP oleh guru SDN Manahan masih banyak kendalanya yaitu dalam hal: (1) pengkajian silabus; (2) perumusan indikator pencapaian KD pada KI1, KI-2, KI-3, dan KI-4; (3) pengembangan materi pembelajaran; (4) penjabaran kegiatan pembelajaran dalam bentuk yang lebih operasional; (5) penentuan alokasi waktu untuk setiap pertemuan; (6) menentukan strategi pembelajaran remedial bagi siswa yang belum tuntas dan enrichment bagi siswa yang sudah lebih cepat tuntas; (7) menentukan media, alat, dan bahan belajar; (8) menentukan narasumber dan sumber belajar; dan (9) pengembangan penilaian pembelajaran. Berdasarkan hasil kuisioner tersebut, kinerja kepala sekolah masih kurang dalam hal membantu guru membuat RPP kurikulum 2013.

Penyusunan RPP yang hanya dilakukan oleh guru secara mandiri yaitu pengembangan materi pembelajaran. Adapun penyusunan RPP yang dilakukan oleh kerjasama guru dalam satu kelompok mata pelajaran yaitu: (1) pengkajian silabus; (2) perumusan indikator pencapaian KD pada $\mathrm{KI}-1, \mathrm{KI}-2$, $\mathrm{KI}-3$, dan $\mathrm{KI}-4$; (3) penjabaran kegiatan pembelajaran dalam bentuk yang lebih operasional; (4) penentuan alokasi waktu untuk setiap pertemuan; (5) menentukan strategi pembelajaran remedial bagi siswa yang belum tuntas dan enrichment bagi siswa yang sudah lebih cepat tuntas; (6) menentukan media, alat, dan bahan belajar; (7) menentukan narasumber dan sumber belajar; dan (8) pengembangan penilaian pembelajaran.

Jadi, peran kepala sekolah SDN Manahan sebagai supervisor tidak menonjol dan masih kurang, hal ini ditandai dengan masih banyaknya kendala yang dialami guru dalam menyusun RPP kurikulum 2013. Padahal, supervisor bekerja untuk membantu memecahkan berbagai permasalahan yang ada, jika masalah masih saja dialami para guru berarti kinerja kepala sekolah masih perlu ditingkatkan.

\section{E. Peran Kepala Sekolah sebagai Evaluator}

Berdasarkan bagan sistem kerangka kerja kepala sekolah dalam manajemen kurikulum dan pembelajaran dari Triwiyanto, semua masukan diperlukan sebagai kondisi awal yang akan diproses untuk mencapai hasil yang diinginkan. Kemudian, hasil dapat diukur melalui produktivitas pendidikan berupa efektivitas dan efisiensinya. Kepala SDN Manahan menjadikan evaluasi diri sekolah dan capaian ujian nasional/sekolah sebagai dasar penyusunan arah dan kebijakan sekolah, kemudian komponen yang menjadi bahan evaluasi kurikulum dan pembelajaran 
yaitu materi pembelajaran, metode, dan sarana prasarana pembelajaran. Tindak lanjut hasil penilaiannya dijadikan sebagai bahan awal dalam menyusun rencana kerja selanjutnya. Kemudian, hasil penilaian guru dianalisis lebih lanjut untuk mengetahui kemajuan dan kesulitan serta dimanfaatkan untuk perbaikan pembalajaran. Hal ini diperkuat oleh Nyabero (2016:62) yang mengatakan "The function of evaluation may be thought of in two ways. At the methodological level, we may talk of the goals of evaluation; in a particular sociological or pedagogical context we may further distinguish several possible roles of evaluation. In terms of goals, we may say that evaluation attempts to answer certain types of questions about certain entities. The entities are the various educational instruments (processes, personnel, procedures, courses etc.)". Pendapat tersebut dapat diartikan bahwa fungsi evaluasi dapat dimaksudkan dalam dua cara. Pada tingkat metodologi, kita mungkin berbicara tentang tujuan evaluasi; dalam konteks sosiologis atau pedagogis tertentu kita dapat lebih jauh membedakan beberapa kemungkinan peran evaluasi. Dalam hal sasaran, kami dapat mengatakan bahwa evaluasi mencoba menjawab beberapa jenis pertanyaan tentang entitas tertentu. Entitas adalah berbagai instrumen pendidikan (proses, personel, prosedur, kursus, dII).

Periode evaluasi terhadap dokumen perencanaan dilakukan per tahun dalam hal: visi, misi, tujuan, rencana jangka menengah dan rencana tahunan. Kemudian, evaluasi pedoman sekolah yang dilakukan per tahun yaitu kurikulum, kalender pendidikan/akademik, struktur organisasi sekolah/madrasah, pembagian tugas di antara guru, pembagian tugas di antara tenaga kependidikan, peraturan akademik, tata tertib sekolah, kode etik sekolah, dan biaya operasional sekolah.

Jadi, peran kepala sekolah SDN Manahan sebagai evaluator tidaklah menonjol karena kepala sekolah hanya menjadikan materi pembelajaran, metode, dan sarana prasarana pembelajaran sebagai bahan evaluasi kurikulum. Padahal seluruh komponen pembelajaran harus dijadikan bahan evaluasi kurikulum agar hasil yang diperoleh sesuai harapan awal penyusunan kurikulum.

\section{KESIMPULAN}

1. Peran kepala sekolah SDN Manahan sebagai pendorong prestasi memang cukup baik, tetapi kepala sekolah lebih berfokus pada pemberian penghargaan kepada siswa dan guru yang telah berhasil mendapatkan kejuaraan.

2. Peran kepala sekolah SDN Manahan sebagai penyusun perangkat kurikulum sangat menonjol. Hal ini dapat dilihat dari banyaknya serangkain aktivitas penyusunan kurikulum yaitu perangkat kurikulum KTSP, 2013, sampai pedoman kegiatan ekstrakurikuler disusun bersama-sama dengan melibatkan semua pihak yaitu guru, komite, tokoh masyarakat. Setelah menyusunnya, kepala sekolah juga memberikan sosialisai kepada pihak-pihak tersebut ditambah sosialisasi kepada orang tua/wali siswa. Kepala sekolah juga melakukan rencana kerja dengan melibatkan semua pihak terkait rencana jangka pendek hingga panjang.

3. Peran kepala sekolah SDN Manahan sebagai pelatih dan pengembang tenaga pendidik dan kependidikan tidak menonjol karena kepala sekolah tidak memiliki strategi khusus dalam melatih dan mengembangkannya. Padahal jika seorang kepala sekolah memiliki strategi khusus maka tenaga pendidik dan kependidikan lebih mudah terarah dalam melakukan rencana kerja sesuai harapan.

4. Peran kepala sekolah SDN Manahan sebagai supervisor tidak menonjol dan masih kurang, hal ini ditandai dengan masih banyaknya kendala yang dialami guru dalam menyusun RPP kurikulum 2013. Padahal, supervisor bekerja untuk 
membantu memecahkan berbagai permasalahan yang ada, jika masalah masih saja dialami para guru berarti kinerja kepala sekolah masih perlu ditingkatkan.

5. Peran kepala sekolah SDN Manahan sebagai evaluator tidaklah menonjol karena kepala sekolah hanya menjadikan materi pembelajaran, metode, dan sarana prasarana pembelajaran sebagai bahan evaluasi kurikulum. Padahal seluruh komponen pembelajaran harus dijadikan bahan evaluasi kurikulum agar hasil yang diperoleh sesuai harapan awal penyusunan kurikulum.

\section{SARAN}

Tugas kepala sekolah yang berkenaan dengan manajemen kurikulum dan pembelajaran berhubungan dengan kompetensi kepala sekolah dalam memahami sekolah sebagai sistem yang harus dipimpin dan dikelola dengan baik, diantaranya pengetahuan tentang manajemen itu sendiri. Oleh karenanya, pepala sekolah harus memahami bahwa dirinya harus mampu menunjukkan upaya dalam meningkatkan output sekolah, yaitu kualitas, produktivitas, efisiensi, dan inovasi.

\section{DAFTAR PUSTAKA}

Alkahtani, A. (2017). Curriculum Change Management and Workload. Journal of Improving Schools, 1-13, DOI: 10.1177/1365480217706789

Chitrangsan, N., Sawekngam, W., \& Thongthew, S. (2015). Development of A Curriculum Management Process by Applying Lean Concept for Waste Elimination to Enhance Curriculum Implementation of Primary School Teacher. The Annual International Conference of the Bulgarian Comparative Education Society, Jun 10-13, Page 161-168.

Dean, J. (2002). Managing The Secondary School. Newyork: Routledge.

Nyabero, C. (2016). Toward A Collective Approach to Course Evaluation in Curriculum Development, Acontemporary Perspective. Journal of Education and Practice, Vol.7, No.35.

Pata, K., dkk. (2016). Three Curriculum Maturing Cycles in Academic Curriculum Management Systems, Springer International Publishing Switzerland, 620, 289300. DOI: 10.1007/978-3-319-42147-6_24

Rusman. (2011). Manajemen Kurikulum. Jakarta: Rajawali Press.

Salmiati.,\& Afrizal, A. (2018). Upaya Kepala Sekolah Dalam Meningktakan Prestasi Belajar Siswa Sebagai Motivator Di Sdn 19 Banda Aceh. Jurnal Tunas Bangsa, Vol. 5, No. 1.

Sobri, A.Y. (2013). Pembinaan Profesionalisme Guru dalam Meningkatkan Kualitas Pembelajaran. Jurnal Manajemen Pendidikan (Maret), Volume 24 (1):9-20.

Syafrizal, F. (2016). Peran Kepala Sekolah Dalam Pengembangan Manajemen Sekolah Sebagai Upaya Meningkatkan Mutu Pendidikan Di Sd Plus Islam Excellent Bukittinggi. Jurnal Manajemen, Kepemimpinan, dan Supervisi Pendidikan, Volume 1, No. 2, Juli-Desember.

Triwiyanto, T. (2015). Manajemen Kurikulum dan Pembelajaran. Jakarta: Bumi Aksara.

Zaitseva, L., Bule, J., \& Makarov, S. (2013). Component-Based Approach In Learning Management System Development. Proceedings of the IADIS International conference e-Learning 2013, Prague, Czech Republic July 23 - 26, 2013. 